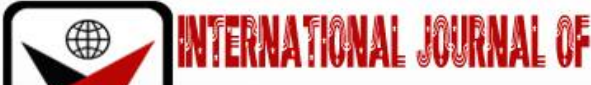

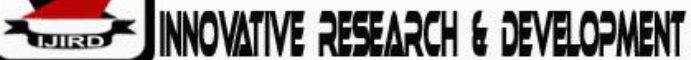

ISSN 2278-0211 (Online)

\section{The Communicative Functions of Tanzanian Online Newspaper Headlines}

\begin{tabular}{|c|}
\hline Nasibu M. K. Musa \\
Ph.D. Candidate, Department of Languages, Linguistics and Literature, \\
Rongo University, Kenya \\
Dr. Gechemba Damaris Nyakoe \\
Lecturer, Department of Languages, Linguistics and Literature, \\
Rongo University, Kenya \\
Dr. Kenneth Odhiambo \\
Lecturer, Department of Languages, Linguistics and Literature \\
Maasai Mara University, Kenya \\
\hline
\end{tabular}

\begin{abstract}
This paper sought to analyse the communicative functions Tanzanian online newspaper headlines. A sample of Mwananchi and The Citizen dailies was obtained purposively from10 Tanzanian registered online newspapers. Also, the corpus of 259 front page headlines was randomly collected from the two digital papers. Using a checklist, the study collected and analysed data from the online newspaper headlines with SPSS version 20. The study revealed that $69.9 \%$ of the two daily newspaper headlines observed the traditional communicative function of a newspaper headline that requires the headline to informative and summarise the articles it represents. However, a small fraction of newspaper headlines appeared to be less informative, ambiguous and vague, and metaphorically constructed in that readers could only understand their intentions either by clicking or reading the full articles or infer the meaning through contexts. The study concluded that the use of less informative headlines was the marketing strategy that the digital newspaper writers used to draw the attention of readers. The study recommended carrying out the study on how the newspaper headlines published impacted readership and visibility on the search engines and social platforms.
\end{abstract}

Keywords: Online newspaper headlines, communication, in formativeness

\section{Introduction}

Every newspaper article should have a heading. Normally, a newspaper headline acts as the title of the news that is set in big and bold letters to introduce the news article (Van Dijk, 1988; Dor, 2003; Saxena, 2006; Ifantidou, 2009).It is therefore a very important section that introduces the news article and attracts the newspaper readers by telling them shortly and interestingly what the story is about (Bell, 1991 \& Nir, 1993) and people usually read the title of an article before they can read the full story. A typical newspaper headline has two basic functions-summarising the article introduced and drawing the attention of the readers (Dor, 2003; Saxena 2006). This suggests that a headline that summarises the article it represents is more informative and the headline that attracts the attention of readers is likely to be more creative and imaginative. According to Bonyadi and Samuel (2013), those newspaper headlines which are informative and attractive can easily help the newspaper readers grasp the meaning of the news. Ifantidou (2009) asserts that newspaper writers optimise relevance of their headlines by making them informative and interesting to readers. This relevance optimisation can be interpreted in the framework of Relevance Theory by Sperber and Wilson (1986/1995) ostensive inferential communication layers of intentions. The informative function in this paper was defined as the intention to inform audience of something (informative intention) and the function of drawing the attention of readers as the intention to communicate the intended information (communicative intention).This paper therefore sought to confirm the practical function (intention) of Tanzanian online newspaper headlines of Mwananchi and The Citizen.

\subsection{Relevance Theory and Newspaper Headlines}

This paper was based on Dan Sperber and Deirdre Wilson Theory of Relevance that was developed in 1986 and revised in 1995 in an attempt to interpret utterance communication. Initially, the relevance theory was developed out of H.P Grice's idea but has ever since turned into a pragmatic and cognitive theory. This theory aims at explaining that people usually communicate much more information with their words than what is contained in their literal meaning. According to Sperber and Wilson (1995), the acts of people's communication are ostensive in that they draw their audience's attention that a writer/speaker intends to communicate particular information. In this regard, the writer/speaker believes that a certain utterance is relevant to the people addressed. In the technical sense, a relevant utterance is that which 
makes people understand the meaning at the minimum processing cost for the audience. The Relevance theory fitted in this study for helped to usto understand the practical communicative functions of the Tanzanian online newspaper headlines.

The Relevance Theory is governed by the two major principles: The cognitive principle and communicative principle. According to Sperber and Wilson (1995), the cognitive principle of relevance states that 'human cognition tends to be geared to the maximisation of relevance' (p.260). In this regard, the digital newspaper writers try their best to maximise the relevance of their newspapers so that readers can understand them at the low processing cost. In other words, the more relevant the newspaper headline becomes the easier it is for readers to conclude. The second principle states that every utterance conveys the information that it is relevant enough to the audience and the most relevant one is compatible with the interlocutors' preferences and abilities (Sperber \& Wilson, 1995p. 270). In the newspaper discourse, if the newspaper headline contains very few positive cognitive effects for the readers with respect to the processing efforts required to achieve the said effect, the news consumers cannot take the trouble to process it, and this implies that the journalist wouldn't have taken time to design an irreverent headline. Thus, a journalist designs a newspaper headline that requires less processing effort to achieve more positive cognitive effects on newspaper readers - to convey the intended meaning. On balance, journalists intend to be understood by readers easily.

In relevance theory, ostensive behaviours such as verbal communication--- the act of speaking and writing) and non-verbal communications (facial expression, posture, nodding) normally signal the intention to communicate something to the audience and tend to draw the readers' attention to the headline news. In ostensive inferential communication, this is what we call the communicative intention. On the other hand, the informative intention is the intention to convey the said information, i.e. the real message of the communication. In the newspaper headlines, ambiguity, vagueness, and metaphors are communicative intentions for they draw the attention of newspaper readers on the internet (pragmatic intention) and the informative headlines have the intention to inform the audience (acting as an abstract of the news). Based on the cognitive and communicative principles of the Relevance Theory, this study sought to analyse the communicative intentions of the Tanzania online newspaper headlines.

\section{Literature Review}

The newspaper literature covers a wide range of theoretical and empirical subject matters such as the grammar of headlines, effects of headlines on news comprehension, and recall (Dor, 2003). In addition, Kuiken et al. (2007) and Dor (2003) argue that the literature of a newspaper discourse has hardly explicated the nature of the communicative act that a headline performs in the digital environment. In designing headlines, designers normally select a few words that can adequately inform or communicatethe intended messagein the article. In print media, for example, the designer of a newspaper headline may consider the space available, choice of word, and clarity before publishing the headline (Culpeper et al., 2009). However, in the digital age, headlines should have searchable words on different search engines and that will lure readers to click and read more on the internet (Morgan, 2009). Thus, Search Engine Optimisation (SE0) seem to be an imperative factor for online communication because online newspaper writers do not just create informative and creative headlines, they also consider keywords that newspaper readers can use to access the information they want. This section, therefore, reviews studies on the communicative functions of a newspaper headline discourse.

A headline plays a significant role in newspaper communication. Normally, journalists view any headline as a riveting shortcut to the contents of newspapers and it performs two basic functions of summarising and drawing the attention of the readers to read the full text of the newspaper article (Saxena, 2006; Dor, 2003). Van Dijk (1988) argues that primarily, news headlines recap the story they represent. However, Dor (2003); Bell (1991) and Nir (1993) hold that some headlines do not always recap the stories they represent. Instead of summarising the story, they pay little or no attention to the primary function of a newspaper headline. Dor (2003) argues that even the classical and quality newspapers, headlines rarely recap the articles they introduce (Dor, 2009). What they do is just to highlight one aspect obtained out of the story or provide a heading with a quotation to promote the materials that are out of the news article itself. Bell (1991) on the other hand makes a distinction between a headline that acts as an abstract of the article and a headline that focuses on a less important incident or aspect. Nir (1993) also provides a dichotomy of newspaper headlines: (1) headlines that summarise the story and (2) headlines that promote one of the details of the story. According to Lindeman (1990), sensational and tabloid newspaper headlines make use of poetic terms. Regarding the arguments under this section, it is evident that newspaper headlines either act as abstracts of the stories or draw the attention of readers. Based on this conclusion, this study, therefore, sought to check whether the current online Tanzanian online newspaper headlines were still observing the primary communicative functions of online newspapers that require a headline to be informative by summarising the article or the pragmatic function where headlines provoke the readers to click on the news introduced by the headline. In contemporary online newspaper headlines, journalists tend to incorporate the most striking language features such as ambiguity, vagueness, and metaphor which differentiate the newspaper language from that of the ordinary language. These features in ostensive inferential communication are devices that online journalists use to design their headlines.

Newspapers are categorised as either being tabloid or broadsheet. According to Dor (2003), the function of the tabloid headline is different from that of a broadsheet because the tabloid headline provides the paper consumer with a fairly complex conundrum which triggers frames and belief systems in the reader's mind, and, then, gets resolved in the ensuing text. In other words, tabloids seem to have an additional practical pragmatic function. This is based on the fact that a newspaper headline should catch the attention of the readers and provoke them to read the full article (Dor, 2003; Bell, 1991; \& Nir, 1993). Thus, a headline should not just summarize the story but it should as well attract its readers. According to Iarovici and Amel (1989), a newspaper headline has a double function. The present study, therefore, sought to examine 
whether the online newspaper headlines were still adopting the basic traditional functions or intentions of print newspaper headlines of summarising articles or taking the pragmatic function approach in the digital environment.

\subsection{Ostensive Inferential Communicative Devices in Newspaper Headlines}

In Linguistics, ambiguous, vague and metaphorical constructions are always considered difficult to understand to readers for they allow multiple understanding (Khamahani \& Tahirov, 2013). Similarly, Perfetti et al. (1987) argue that newspaper headlines lead to comprehension problems since they are syntactically impoverished and, as a result, they have syntactic ambiguity. However, such kinds of constructions are very important tools in achieving some communication goals in other disciplines. In the online newspaper discourse, for example, ambiguity and vagueness are devices that the digital journalists use to construct online newspaper headlines (Ifantidou, 2009; Brône \& Coulson, 2010; Bucaria, 2006). This strategic deployment of ambiguity in newspaper discourse is a pragmatic-linguistic device that intends to convey the news that is compatible with news outlets and public interests. The use of these devices is, therefore, a trick that forces online newspaper readers to click and read the full article. In ostensive inferential communication of Relevance Theory by Sperber and Wilson (1986), ambiguity, vagueness and metaphors are communication tactics that intend to draw the attention of online newspaper readers. This is based on the fact that online newspaper readers are aware of the fact readers can hardly understand vague and ambiguous expressions by just scanning the headline unless they click to download the article introduced or use ad hoc concepts and ad hoc context. This makes it advantageous for a reader to use non-linguistic information as quickly as possible in comprehension. The assumption made in this paper is that vague, ambiguous and metaphorical constructions are devices that the online journalists use to design newspaper headlines contain deliberate ambiguity or vagueness and according to Khamahani and Tahirov (2013) newspaper readers may not be aware of the diverse categories of vagueness and ambiguity created by particular linguistic features. This study, therefore, sought to use the Relevance Theory by Sperber and Wilson (1986/1995) to explain how of different types of ambiguities, vagueness and metaphors are used with online newspaper headlines.

\subsubsection{Ambiguity}

According to Handke (2003), ambiguity is the phenomenon where a linguistic expression allows more than one interpretation. Ifantidou (2009) argues that those newspaper headlines which appear to have multiple encodings are ambiguous. Ambiguity can be used in at least two senses: uncertainty (dubiousness) or a sign bearing several meanings. In this study, an ambiguous headline is that headline that enjoys multiple interpretations (Sennet, 2016). In ostensive inferential communication of Relevance Theory, ambiguity is seen as the device that journalists employ to attract clicks on the internet. When designing headlines, the digital journalists create ambiguous news titles that violate or flout Grice's (1975) maxims of clarity for they have multiple interpretations. Ambiguity can be classified into six different types: lexical ambiguity, structural ambiguity, phonological ambiguity, referential ambiguity, scope ambiguity, and pragmatic ambiguity (Handke, 2013; Sennet, 2016). This analysis of the ambiguity of headlines in this paper was based on the aforementioned types of ambiguities that journalists use to design their digital newspaper headlines. According to Handke (2013) and Sennet (2016) for example, a lexical item may contain homophonous entries or even co-spelled, but with different meanings. According to Ifantidou (2009), a reader should use the contextual background knowledge or read the whole article that follows the headline they want to understand the actual meaning of the headline. In relevance theoretical framework, the news consumers can reduce ambiguity by either reading the whole article represented by the headline or using the contextual background knowledge to understand the intended meaning. In ostensive inferential communication layers (Sperber \& Wilson, 1995), the writer of the headline must have an intention to inform the readers of something. They use ambiguity as the strategy to entice readers to read the full version of the article. This study sought to identify and classify online newspaper headlines with multiple interpretations.

Bucaria (2006) and Alagbe (2009) studies have shown that newspaper headline designers exploit syntactic and lexical ambiguity to create headlines and journalists distort the meaning by manipulating the headline clarity to that of vagueness. Khamahani and Tahirov (2013) as noted earlier, claim that in Linguistics, ambiguity is considered as a problem, but in newspaper headline discourse, ambiguity provides value as the device that draws the attention of the newsreaders. Ambiguity must have a source. Marquez (1980) indicates that the daily newspapers with the tabloid format had a good number of confusing and ambiguous headlines than the quality newspapers. Nwala's (2017) study on the meaning of Nigerian newspaper headlines found out that newspaper headline is a kind of in-house journalistic readership promotion strategy and readers could only interpret the newspaper headlines after reading the full article was read. Unlike the previous studies, the current study focused on creative language use that exploits ambiguity for online newspaper headlines.

\subsubsection{Vagueness}

Vague expressions or utterances are normally unspecified about their meanings (Handke, 2013; Sabet \& ,Zhang In this re .(2016gard, vagueness allows unspecified meanings and creates a broad space for interpretation among readers (Kempson, 1977; Frawley, 2013). Handke (2013) however, claim that vague expressions should not be confused with ambiguous expressions. Handke presents the distinction between ambiguity and vagueness that, an ambiguous expression, the context selects one of the senses of a given word or an expression whereas, in vagueness, it is hard to notice ambiguity because the context clarifies the intended meaning. Therefore, the context adds information to the word sense. In vagueness, the meaning is always fuzzy, unclear, unspecified, and blurred (Frawley, 2013 \& Handke, 2013). Gilmore (2016) reports that journalists deliberately use vague constructions which aim to entice readers to read the whole story. Vagueness under this study was considered as one of the marketing devices for online newspaper headlines. Guo, 
Tieying, and Gimeno (2017) support the argument that vagueness is a communication device in marketing. In relevance theoretical framework by Sperber and Wilson (1995), a vague construction is an ostensive inferential communication stimulus that online journalists use to design online newspaper headlines. In this study, the analysis of vagueness of online newspaper headlines adopted Kempson's (1977) taxonomy of vagueness: referential, indeterminacy, lack of specification, and disjunction. According to Kempson, the online newspaper headlines with referential vagueness have lexical items that are very clear enough but it might be hard for readers to decide whether the lexical item applies to certain objects or not (Kempson, 1977). In referential vague headlines, it is hard for readers to find a borderline of the object that the digital journalist is trying to refer to. The indeterminacy type of vagueness a headline interpretation appears to be intangible (Kempson, 1977; Handke, 2013). Kempson (1977) argues that indeterminacy is common in possessive constructions and journalists use indeterminate newspaper headlines to create online readership.

Metaphor: In cognitive semantics, metaphor is defined as 'an inherent and fundamental aspect of semantic and grammatical structure' (Langacker, 1987. p.100). This definition differs from the traditional understanding of metaphor as a special, additional property of a certain expression, which is related to imaginative or artistic usages of language rather than with ordinary speech. Traditionally, metaphor is a type of literary device and rhetorical-the language usage skill to accomplish a certain goal, in particular, to persuade people, not of linguistic description (Ricœur, 1975). However, a tradition of the study of metaphor initiated by Lakoff and Johnson (1987) has confirmed the ubiquity of metaphor in ordinary language and appeal that it plays a significant role in language structure. Based on the aspect of metaphor, this study sought to examine the imaginative and artistic use of language in online newspaper headlines. The metaphor was associated with creative, imaginative, and artistic language usage rather than with ordinary daily language use. Under relevance theoretical framework by Sperber and Wilson (1986), metaphors are relevance optimisers thus digital journalists use it as a coercive device to attract people to click on the newspaper headlines.

Although most of newspaper readers are not aware of metaphors, they are used by the digital journalists to convey their communicative intentions to the readers (Lakoff and Johnson, 1987). As stated by the pragmatic function of newspaper headlines by Saxena (2006), the headline designer opts for creative and imaginative language use, metaphor in this case, as the device to attract online news consumers. Equally, this study used metaphor to suggests that metaphor is a cognitive process that helps people conceptualize their experience by 'setting up correspondences between easily understood things like burdens and hard to understand things like obligations.' (Riemer, 2010, p. 258). As it is for MolekKozakowska (2014), the study incorporated the cognitive and pragmatic approaches to examine a metaphor as both a conceptual element of news representations and a device of strategic framing of online newspaper headlines.

In traditional metaphorical language use, word information can be associated with object similarity or contiguity (Fite, 1900). Based on similarity, metaphor refers to a linguistic representation whereby the appearance of new meaning is the result of the association of two objects due to their resemblance. According to Geeraerts (2010), metaphors normally refer to similarity of shape or appearance and structural position. On the other hand, metaphors by contiguity refer to metonymy whereby two referents, one of which makes part of the other and is closely connected to it. This study considered both metaphors of similarity and contiguity as they appeared in newspaper headlines.

The studies by Haiyan (2013) and MoleK-Kozakowska (2014) have attempted to explore the occurrence of metaphorization in newspaper headlines. The study admitted that metaphor was not just a conceptual representation of social realities but also the coercive device adopted by journalists to achieve optimal relevance in ostensive communication and fulfil their writing purposes. Shie (2011) addressed the cognitive, pragmatic, and rhetorical functions of conceptual metaphors and metonymies in Times Supplement and New York Times newspaper headlines with the focus on variations in non-lexicalized metaphors and metonymies. The study revealed that non-lexicalized metaphors and metonymies represented a relevant pragmatic or stylistic interesting aspect of the article, guided pragmatic inference in headline interpretation. Thus, study adopted qualitative analysis metaphors excerpted from Mwananchi and The Citizen online newspaper headline to illustrate how the Tanzanian digital paper writers exploit both metaphors of similarity and contiguity.

\section{Methodology}

This paper was based on the analytical and cross-sectional designs. Using the qualitative and quantitative approaches, this study involved a population of 10 online newspapers in Tanzania whereas Mwananchi and The Citizen newspapers, both from Mwananchi Communication Limited (MCL) formed the sample. From the two newspapers, a sample of 259 out of 730 front-page headlines published from 2017 July to June 2018 was taken. In a pilot study, it was revealed that the two dailies had a good record of online newspaper readership metrics. Mwananchi was purposively chosen to represent the Swahili newspaper audience in Tanzania and The Citizen for English audience in the country. Also, the papers under this study were selected for they fell under the category of the quality newspapers which had wide content coverage and enjoyed readership in Tanzania (Khalifa, 2018 \& MCT, 2018). Yamane's (1967) formula for sample size was used to sample 259 headlines out of 730 headlines. The $95 \%$ confidence level was chosen in the formula and that was equivalent to a 0.5 significance level. According to Yamane's formula, the $95 \%$ confidence level is always adequate to make the optimal sample size and reliable results. Table 1presents the statistics of headlines from the two dailies. 


\begin{tabular}{|c|c|c|}
\hline & Frequency & Percent \\
\hline Mwananchi & 129 & 49.8 \\
\hline The Citizen & 130 & 50.2 \\
\hline Total & 259 & 100.0 \\
\hline
\end{tabular}

Table 1: Sampled online Newspapers and Headlines

Source: Field data, 2019

Table 1shows that 50.2 percent of 259 of newspaper headlines selected were obtained from Mwananchi whereas 49.8 percent were from The Citizen. Thus, both papers were equally represented in the study.

This study collected data from Mwananchi and The Citizen websites with achecklist and headlines obtained were coded from 1 to 259 to ease SPSS analysis. During the data collection, the codes ( 1 = Mwananchi, $2=$ The Citizen) were used to specify the types of newspapers, $(1=2017$ or $2=2018)$ for the year of publication codes and (1-12) codes for the month of publication. The content analysis considered the two major functions of a newspaper headline (summarising the article introduced and drawing the attention of the headline readers) which were available in the literature. To address the issue of newspaper headline communicative functions, the study created four variables in the checklist. Variable one [1] was for headlines that were informative but not creative; variable two [2] for creative, but not informative headlines, variable [3] for headlines that were both creative and informative, and variable [4] for headlines that were neither creative nor informative. Then, all 259-newspaper headlines were examined with reference to the four variables stated. Thereafter, the variables were coded, recorded and analysed with SPSS. The creative headline was defined as jokey, entertaining, humorous, punning, rhyming, using implicit rather than explicit meaning and exhausting literary styles. However, not creative headlines were described as using plain and explicit language, and there was no use of literary devices. The informative newspaper headlines on the other hand were described as being clear, unambiguous, precise, short and relevant. Thus, they could allow skipping newspaper story reading. Finally, the less-informative headlines were defined as ambiguous and vague, deceiving, and logically irrelevant, hence attracting news story reading. Then, the creative language devices of ambiguity, vagueness, metaphors and other stylistic devices were the basis for creative languages.

\section{Findings and Discussion}

To determine the practical communicative functions of online newspaper headlines, the study considered the compliance and non-compliance of the traditional basic functions of the print newspaper headlines in the digital setting. This study was based on the claim that newspaper headlines pursue two basic traditional functions; to summarise the article it represents, and to draw the attention of newspaper readers. In Relevance Theory by Sperber and Wilson (1986), the digital newspaper writers optimise relevance of their newspaper headlines to attain their communicative goals in the digital setting. They do so by creating an informative and relevant headline to allow readers to smoothly process the input and produce the maximal positive cognitive effects. Also, the headline writers always have two intentions- intention to inform readers of something and intention to communicate the information. They achieve their communicative intentions by making sure that a headline summarises the article (informative intention) and they their communicative intentions with click bait devices that normally provoke readers to click and open the news. In this section, the findings on the practical functions of online newspaper headlines are presented hereunder.

In data shows that the Mwananchi and The Citizen newspapers were still complying with the traditional function of designing newspaper headline where the writer summarises the article introduced by 69.9 percent (See figure 1 below). Figure 1presents the results on informativeness of newspaper headlines.



Figure 1: Percentages of in Formativeness and Creativeness of Online Newspaper Headlines

Source: (Field Data, 2019)

Figure 1.1 indicates that $69.9 \%$ out of 259 online newspaper headlines were informative but not creative, $10 \%$ were creative but less informative, $4.6 \%$ were both creative and informative, and $15.4 \%$ were neither creative nor informative. The results concluded that the majority of online newspaper headlines published by Mwananchi and The Citizen were informative but not creative. According to the descriptors of informative headline in the checklist, such 
headlines could allow readers to skip reading the full story. This means Mwananchi and The Citizen newspapers editors preferred plain, clear and explicit languages. That is, most of the online newspaper headlines acted as the abstracts of the entire articles they represented. In other words, the headline designers intended to inform rather than to draw the attention of readers.

\subsection{Informative Online Newspaper Headlines}

As noted earlier, most of headlines under this study were informative but not creative. The traditional intention of a headline has been to summarise the newspaper article it introduces precisely (Dor, 2003; Saxena, 2006). To meet this traditional function, the digital journalist had to design an informative headline, which could not necessarily require readers to read the full article. In other words, they designed the informative newspaper headlines that acted as the abstracts of the stories they represented. By being informative, the newspaper headlines contained standard, clear, precise and explicit languages, thus making it is easy for news consumers to comprehend the substantial information by just reading a headline alone. The data set in [1a-b] below is an illustration of the informative but not creative headlines extracted from The Citizen newspaper.

[1] a. Magufuli urges Tanzanians to emulate Nyerere's patriotism. (The Citizen, October 14, 2017)

b. President Magufuli appoints Dr Slaa new ambassador. (The Citizen, November 24, 2017)

Source: (Field data, 2019)

Headlines in the data set [1.a-b] above are informative as they provide all the necessary information. Also, the headlines are plain, clear with explicit language. Apart from using clear and explicit language, the headlines have complete thoughts as full sentences. Since the headlines in the data set above are informative, they may not attract readers to read the full article they summarise. The language of two online newspaper headlines in the data set in [1a-b] is very clear, precise, and relevant to the articles they introduce. According to Ifantidou (2009), the headlines with explicit meanings tend to prevent readers to reading the full articles.Thus, the newspaper headlines with explicit meanings under this study observed the primary traditional function of the print newspaper headlines for they summarised the stories they represented. The finding on the informative function of a newspaper that requires a newspaper headline to be informative is confirmed by the assumption by (Bell, 1991; Van Dijk, 1988; Dor, 2003; Saxena, 2006) that claim that a headline is a riveting shortcut to the contents of a newspaper. Thus, all news articles must have headlines that recap the story they represent. Therefore, Mwananchi and The Citizen headlines complied with the traditional communicative function of a headline of summarising the article they introduced.

The cognitive principle under Relevance Theory (Sperber \& Wilson, 1986; Wilson \& Sperber, 2004; Sperber and Wilson, 2008) informative headlines have relevant to readers because they require little process efforts to produce the positive cognitive effects. In this regard, newspaper headline readers in data set (1a-b) could easily understand the concepts contained. The Communicative Principle of Relevance Theory by Wilson and Sperber (2002) states an ostensiveinferential communication requires the informative intention (the intention to inform the audience of something) and the communicative intention (the intention to inform the audience of one's informative intention). In this regard, the designers of the online newspaper headlines in data set (1a-b) intended to be informative to their readers by overtly communicating their intentions in a clear and plain language with online headlines.

\subsection{Creative and Imaginative Online Newspaper Headlines}

Contrary to the first informative newspaper headlines, the creative headline under this study were defined as playful, entertaining, vague, ambiguous, humorous, punning, using figurative language, rhyming, using implicit rather than explicit meaning and exhausting literary styles. It was assumed that the attention-drawing headlines had to be creative, imaginative and less informative, ambiguous, vague and implicit. The creative and imaginative headlines would bait readers to read the full story. To make the headline creative and imaginative, newspaper writers had to exhaust the highest level of creativity and imagination to attract more online newspaper readers (Van Dijk, 1988). In other words, the headlines under this category employed journalistic writing and creativity, poetic and stylistic devices (Crystal, 1987). Under this section, the indicators of creativity and imaginations are limited to ambiguous and vague expressions because, in Linguistics, ambiguity and vagueness are considered as hindrances of comprehension to readers for they have more than one interpretation (Khamahani \& Tahirov, 2013). This study therefore attempted to analyse ambiguity, vagueness as well as metaphors that journalists of Mwananchi and The Citizen digital papers used to creatively construct online newspapers headlines. The subsequent sections will highlight the different forms of ambiguities observed in newspapers headlines under this study.

\subsection{Ambiguity as the relevance Optimiser of Online Newspaper Headlines}

The analysis of ambiguity under this study relied on the available literature on the types of vagueness. Therefore, six different types of ambiguity: lexical ambiguity, structural ambiguity, phonological ambiguity, referential ambiguity, scope ambiguity and pragmatic ambiguity (Handke, 2013; Sennet, 2016) were the basis for the classification. When going through the Tanzanian online newspapers, the study observed that some of the ambiguities appeared in the digital newspaper headline discourse.

\subsubsection{Lexical Ambiguity}

The study observed several lexical ambiguities in the digital newspaper headlines. According to Handke (2013) and Sennet (2016), a lexical item may contain homophonous entries or even co-spelt, but with different meanings. The data set in [2] below is an illustration of the ambiguous headlines extracted from Mwananchi online newspapers. 
[2] a. TRA yatishia kuuza mali za Makonda. (Mwananchi, May 17, 2018)

(TRA threatens to auction Makonda's properties.)

b. Putin ataka kuachana na matumizi ya dola. (Mwananchi, May 9, 2018)

(Putin wants to renounce the use of dollars or Putin wants to get away with power use)

: Field data (2019)

The Swahili newspaper headline in the data set [2.a] above is ambiguous and less informative. In the Tanzanian context where the Swahili language is dominant, the word Makonda could either refer to the nameof the former Dar es Salaam Regional Commissioner (RC), Honourable Paul Makonda or the short form and informal way of naming bus conductors in Tanzania. This ambiguity stems from the Swahili word Makonda. The word has multiple encodings and is likely to allow news consumers to go ahead and read the full article so as to reduce ambiguity or use contextual background knowledge to processes the meaning. The readers with contextual information about Makonda could easily understand the headline. The designer seems to have purposively created an ambiguous online newspaper headline to confuse and attract readers to continue reading the entire article.

For example, the Swahili word dola in the data set (2b) is a homophonous entry with different senses. According to the Online Oxford Living Dictionaries, Kamusi ya Kiswahili, the Swahili noun dola can refer either to the currency (\$) used in nations such as the USA, Canada, and other countries or supremacy (rule) in a certain nation. Therefore, the headline could either mean the current Russian president (Vladimir Putin) wished to stop using the Dollar currency (\$) or end exercising the power vested to him as the president of Russia.According to Ifantidou (2009), to understand the actual meaning of such headline, a reader would need to use the contextual background knowledge or read the whole article that follows the headline.

It was not clear whether ambiguity was deliberate or not but The Mwananchi newspaper headline writers probably intended to confuse newspaper readers with multiple encodings (ambiguity) so that they could not skip reading the whole article. This is because the headline designer deliberately failed to specify dola as many countries such as Canada, Zimbabwe and the USA use the dollar as their currency as well. To reduce ambiguity, the news consumers had either to read the whole article represented by the headline or use the contextual background knowledge to understand the intended meaning. In ostensive inferential communication layers (Sperber \& Wilson, 1995), the writer of the headline had an intention to inform the readers of something but used ambiguity as the strategy to entice readers to read the full version of the article. Since the above-mentioned headline was optimised to be relevant, the readers would easily infer meaning through the context or click to read the full news article.

\subsubsection{Structural Ambiguity}

The other type of ambiguity observed under this study was structural. In structural ambiguity (grammatical ambiguity), the multiple meanings of the whole sentence depend on the structure of the sentence (Handke, 2013; Sennet, 2016). In Linguistics, Semantics, in particular, structural ambiguity is also referred to as syntactic ambiguity. The data set in [3] is an illustration of structural ambiguity in some newspaper headlines.

[3]a.Uokoaji wa helikopta waanza Mlima Kilimanjaro. (Mwananchi, April 4,2018)

(The helicopter rescue services begin at Mount Kilimanjaro.)

b. Project to use Khanga to raise environmental awareness. (The Citizen, August 4, 2017)

Source: Field data (2019)

The Mwananchi newspaper headline in the data set [3.a] is structurally and syntactically ambiguous because the whole headline has two sentential grammatical interpretations that: (1) the services of rescuing a helicopter had begun at Mt. Kilimanjaro and (2) the services of rescuing people in confinement or danger with the help of a helicopter at Mt. Kilimanjaro had begun. The Mwananchi digital journalist seemed to have intentionally tried to confuse readers with structural ambiguity in newspaper headline so that they could proceed reading the entire story. Likewise, the headline Project to use Khanga to raise environmental awareness in the data set [3b] is grammatically ambiguous. Its ambiguity stems from the lexical item project that affects the whole meaning of the headline. Project as the noun refers to the plan of action to use Khanga in an environmental awareness campaign. However, as a verb, the sentence means to estimate, forecast or plan to use Khanga to raise environmental awareness. Structural ambiguity 'is realized when a particular word or phrase modifies more than one constituent or involves more than one relational association. This appears to be the marketing strategy that the digital journalists use to make their readers read news stories instead reading the headline alone.

Scope ambiguity was another form of ambiguity observed in newspaper headlines under this study. The scope ambiguity occurs when two quantifiers or similar words take the scope over each other in different ways in the meaning of a sentence (Handke, 2003). This section presents some of the headline's examples with this kind of ambiguity. Such kind of ambiguity was observed to be common in headlines with quantifiers, negatives and modals or certain adverbs. The data set in [4] is an illustration of scope ambiguity as evidenced in The Citizen and Mwananchi online newspaper headlines.

[4] a.Anyone against Stiegler's Gorge project will be jailed, says Minister. (The Citizen, May 22, 2018)

b. Tanzania inaweza kuzalisha akina Amadou Gallo. (Mwananchi, June 4, 2018)(Tanzania can produce people like Amadou Gallo)

Source: Field data (2019)

The first interpretation in data set [4a] is that whoever tries to go against Stigler's Gorge project would go to prison and some people might have been likely to go against the project in future. The minister's statement had an illocutionary speech act of a warning. The second meaning is that there was at least one person who was already against 
the project and the minister was informing the public about jailing the people who were against the project. Thus, the journalist who wrote the headline was probably informing people that some people in Tanzania were already against the project and that they would be imprisoned or the headline was warning people with opposing ideas against the Stigler's Gorge project. By designing such kind of headline, the newspaper headline designer probably assumed that the newsreaders would understand the concept after reading the article or considering the context of its publication. Therefore, ambiguity often happened on purpose. In relevance theoretical terms (Sperber \&Wilson, 1995), the writer of the above headline had an intention to inform readers, but he/she used ambiguity strategy to show his informative intention and the information would be interpreted via ad hoc context.

In the data set [4b], the use of 'inaweza'(it can), implies probability or ability. For that reason, the headline could mean that Tanzania can possibly produce people like Amadou Gallo or Tanzania has the ability to create people like Gallo. The first meaning is more on the possibility and suggests that producing people like Amadou Gallo is not a guarantee whereas the second one affirms that Tanzania has the ability to produce people like Amadou Gallo. Therefore, the context determines the meaning of the headline for people with background knowledge or they need to read the whole article in the newspaper.

According to Handke (2013), pragmatic ambiguity appears when the utterance has one clear sense but with a different sense in a context. The headline designers sometimes create headlines, which can have both literal and nonliteral interpretations. The data set in [5] below is an illustration of pragmatic ambiguity as observed in some of the Mwananchi online newspaper headlines.

[5] Mawaziri wanne watemwa. (Mwananchi, July 10,2017)

(Four cabinet ministers have been sacked.)

b. Mkazi Dar Kaa chonjo (Mwananchi, January 29, 2018)

(Dar resident, be careful!)

Source: Field data (2019)

In Swahili, the headlines in the data set [5] have two interpretations. In headline [5a], the literal translation meaning is to spit out the four ministers out of the mouth as someone spits saliva out of his mouth. Logically, it is impossible to spit someone out of someone's mouth regarding the size of the mouth. The second and probably the intended meaning in this context was to sackthe four cabinet ministers. For newspaper readers to understand the real meaning, they should have used the occasional ad hoc concept plus the ad hoc context of the headline. The readers had to infer what the writer was trying to communicate. Similarly, the headline in data set [5b] is ambiguous because it has both literal and non-literal meanings. According to the article introduced by the headline, the writer of the headline was giving a warning to Dar es Salaam residents of theft that was going on that time. Kaa chonjo(be careful) is a literary device that was used to estrange the language of the newspaper so that readers can spend their time to click and read the article or use contextual ad hoc concepts and ad hoc context to disambiguate the headline.

According to Handke (2003), referential ambiguity is the type of ambiguity that happens when an expression in a specific headline denotes two or more properties. The referential ambiguity hails from the confusion between two potential referents in the newspaper headline (Al Janaby, \& Abed, 2011). In referential ambiguity, the meaning intended is sometimes contextually clear. However, this is not always true. The data set in [6] is an illustration of pragmatic ambiguity observed in The Citizen newspaper headlines.

[6] a. Mkuchika outlines his priorities. (The Citizen, October 9, 2017)

b. US president torn between his job and his business. (The Citizen, April 4, 2018)

Source: (Field data, 2019)

The headlines in the data set [6] above have the referential ambiguities: The first meaning in [6a] is that 'Mkuchika outlines his own priorities and the second one means, 'Mkuchika outlines the priorities of someone else'. In this context, the possessive pronoun his has the anaphoric reference to Mkuchika and in another context; it refers to someone else. Likewise, the possessive pronoun his in headline 'US president torn between his job and his business' has referential ambiguity. If the newspaper reader wants to understand the information of a person whose priorities outlined without reading the article, he/she needs to use the background knowledge or read the article that follows the headline. In relevance theoretical framework (Sperber \& Wilson, 1995), referential ambiguity was an ostensive inferential communication intention where the writer intended to inform the audience but s/he intentionally used to referential ambiguity marketing device of attracting readers to read the full story. In ostensive inferential communication as Sperber and Wilson (1995) claim, writers,journalists in this context, intend to convey the message to the newsreaders through ambiguous headlines deliberately with the prior knowledge that the readers will understand the meaning through inferences. The headline designer knows that ambiguity is an ostensive stimulus that makes the newspaper readers read the full article. If the reader fails to read the entire article, he/she will certainly choose and optimise the relevant meaning with the help of background knowledge. Even though Khamahani and Tahirov (2013) see ambiguity as a problem, in newspaper headline design, it provides value as the device that draws the attention of the newsreaders. This supported by Bucaria (2006) and Alagbe (2009) argument that ambiguity distorts the meaning by manipulating the headline clarity to that of vagueness.

\subsection{Vagueness as the Relevance Optimiser of Digital Newspaper Headlines}

In this study, the analysis of vagueness in online newspaper headlines adopted Kempson (1977) and Handke (2013) taxonomy of vagueness which are referential, indeterminacy, lack of specification, and disjunction. In this study, vagueness was observed in some newspaper headlines. The data set in [7] below is an illustration of vagueness as observed in Mwananchi and The Citizen online newspaper headlines. In relevance theoretical framework, vagueness is 
assumed to be an ostensive inferential communication device that the digital Journalist employ to design headlines in the digital setting.

[7] a. Now govt takes back Manji's land (The Citizen, April 26, 2018).

b. CHADEMA: Police are on the way to search Lisu's house

(The Citizen, August 23, 2017).

Source: Field data (2019)

The above headline in the data set [7a] does not specify the government that took Manji's land. It could be the government of Kenya, USA, Singapore and so forth. Besides, the land that the headline designer addressed was not specified. Manji is a proper name, there are so many people with the same name, and those people (with the name Manji) could be having many lands as well. Therefore, the land that the journalist is referring to is still unspecified. For newspaper readers to understand the communication of the headline, they should either click and read the whole article in a newspaper or use the ad hoc context of the expression to get the real meaning. Similarly, the headline in the data set [7b] is vague. The possessive construction 'Lisu's house' is underspecified. It can be describing the house that Lisu owns, the house that Lisu lives in, the house that Lisu likes, the house that Lisu built and so forth.

\subsubsection{Referential Ambiguity}

The first category of vague lexical items considered newspaper headlines with referential vagueness. The headlines with referential vagueness have lexical items that are very clear enough but it might be hard to decide whether the lexical item applies to certain objects or not (Kempson, 1977). Thus, in referential vagueness, it is hard to find a borderline of the object that an individual is trying to refer to. Among the online newspaper headlines, samples that the study observed had some lexical items which Kempson (1977) calls referential vagueness. The data set in [8] below is an illustration of referential vagueness from Mwananchi and The Citizen online newspaper headlines.

[8] a. Askofu aandika waraka mzito kwa Lissu. (Mwananchi, September 12, 2017).

(Bishop writes a weighty secular for Lissu)

b. Two lucky winners gain big from M-Bet draw. (The Citizen, June 29, 2018)

Source: Field data (2019)

The Swahili lexical item mzito (weighty) has a fuzzy boundary. It is very difficult to differentiate what is 'weighty' and 'not weighty'. Weighty is an adjective of degree with the meaning that is always in a scale of a continuum. Different readers could define the weighty secular to Lisu at different degrees of weight. Even the lexical item Askofu (Bishop) is underspecified. There are so many Bishops in Tanzania and the world at large. Therefore, using the lexical item Askofu would force the newspaper headline readers to read the remaining parts of the article or use the contextual and inferential meaning to comprehend the headline.

The headline Two lucky winners gain big from M-Bet draw in data set [8b] contains a lexical item big which is underspecified. Under normal condition, it is not easy to show the borderline between what is big and not big as it is on a continuum scale (positive, comparative and superlative). This adjective of degree (big) refers to the size or amount greater than average of its kind. In relevance theoretical terms, ostensive-inferential communication includes the exploitation of an ostensive stimulus to attract the attention of news seekers (Sperber \& Wilson, 1985/6). Since an ostensive stimulus (vagueness) is intended to attract the newsreader's attention, the headline designers know that the readers will only focus on a stimulus that seems relevant enough. When designers produce a headline with an ostensive stimulus, they assume that it is also relevant enough to be worth processing on side of the readers.

\subsubsection{Indeterminacy of the Meaning}

Another type of vagueness is the indeterminacy of the meaning of an item or phrase, where the interpretation appears to be intangible (Kempson, 1977; Handke, 2013). In this case, the newspaper headline designer may create the unspecified (vague) newspaper headline. Kempson (1977) argues that indeterminacy is common in possessive constructions and journalists of the two newspapers applied vagueness in headlines to create semantic indeterminacy. This study was based on the assumption that journalists tend to use vague headlines, a strategy that makes online news consumers view the page and click on the link containing the information to read the full article. The data set in [9] is an illustration of indeterminacy type of vagueness that the headline designer of Mwananchi and The Citizen newspapers used to attract their online readers.

[9]a. Kanisa la Gwajima labomolewa (Mwananchi, July 9, 2017).

(Gwajima's church demolished)

b. Lisu's condition is deteriorating, says CHADEMA Secretary (The Citizen, September 12, 2017).

Source: (Field data, 2019)

The headlines in the data set [9] are very vague as they refer to several undetermined stuffs and people. The headline [9a] for example, could be describing the church that Gwajima owns, the church that Gwajima built, the church that Gwajima goes to pray, the church that Gwajima leads as the Bishop, the church that Gwajima likes most, the church that Gwajima has been advocating for in public and so forth. Although the newspaper headline seems to be unambiguous, it is very hard to determine the meaning of it if the context is not known. In relevance theoretical framework, newspapers readers can only understand the headline with the help of the background knowledge they have about the church or by going ahead and read the entire story.The journalist could have deliberately applied this kind of vagueness to create humour and attract readers to download the article containing the information. Ifantidou (2009) asserts, '...interesting headlines may be semantically underdetermined to the extent that no information is conveyed, due to vague concepts.' (p.700). 
In data the set [9b], headline Lisu's condition is deteriorating, says CHADEMA Secretaryseems to be vague too. It could mean Lisu's health condition is deteriorating; Lisu's financial condition is deteriorating and so forth. The condition being referred to is vague and readers can have a number of references in reading such kind of a headline. In light of Relevance Theory by Sperber and Wilson (1986), vagueness is a device that the newspaper headline designers used to draw the attention of their readers.

Lack of Specification is a different type of vagueness that stems from a lack of a specific meaning in the lexical item (Kempson, 1977). This study sought to presuppose that the newspaper editors or designers are aware of the fact that unspecified headlines make readers read the full story after reading a headline. The data set in [10] below is an illustration of lack of specification type of vagueness that appeared in Mwananchi newspaper headlines.

[10] a. Mgombea Urais 2015 ashikiliwa polisi (Mwananchi, September 5, 2017).

(2015 presidential candidate held by the police)

b. Msafarawa DC washambuliwa (Mwananchi, August 29, 2017).

(The DC's convoy attacked)

Source: Field data (2019)

In data set [10.a], the headline does not specify the presidential candidate and the country.The word 'presidential' is also spatially underspecified. The phrase presidential candidate can be used to describe the national presidential candidates, the students' presidential candidates at the university, the football association presidential candidates, Tanganyika Law Society (TLS) presidential candidate and so forth. Before designing such headlines, both the designer and readers knew that there were so many presidential candidates in Tanzanian 2015 general elections with Tanzania and the world at large. Furthermore, the country in which the candidate belonged to was not specified for 2015 there were so many presidential elections in different countries in the world. In Relevance Theory by Sperber and Wilson (1995), headlines are relevance optimisers. Despite being vague, the writer thought it to be relevant. Regarding the ostensive inferential communication, the writer intended to inform the readers through the headline. However, the writer might have employed a vague headline deliberately as the strategy to entice readers to read the full version of the article or use the ad hoc concept in ad hoc context to interpret.

In data set [10b] above, there are lexical items that are underspecified. For example, the abbreviation DC is not specified and is unconventional in the world. Besides, the DC that the journalist refers to is underspecified. Of course, the acronym DC in Tanzania stands for District Commissioner and for a person who is not a Tanzanian; the word would be difficult for him to comprehend. Even for Tanzanians, the acronym DC can be difficult for readers because there are more than 100 district commissioners in the country. The same headline in the data set [10b], the journalist did not even specify the weapons that assailants used to attack DC's convoy. The weapons could be nuclear, biological or chemical and so forth. Moreover, the journalist employed the passive construction and did not indicate the attacker of DC's convoy.To make it more specific, the headline designer would have probably specified the weapons that the invaders used to attack the District commissioner's convoy. The informative digital newspaper headline would have contained weapons such as guns, bombs, and stones and headline designer would have exposed and specified the attackers. According to Relevance Theory by Sperber and Wilson (1986/1995), uninformative headlines such as those found in data set [10] can be relevant for the designer and the target audience as long as they need the minimal processing efforts and yield the positive cognitive effects. The headline designers did not create such unspecified and vague headline by chance. The designer was aware that by not specifying the weapons and the attackers would make the news consumers either use the context to processes the meaning or read the information after the headline. In ostensive inferential communication by Sperber and Wilson (1995), a vague headline is a strategy of drawing the attention of readers. If the journalist had created the informative headline, this would probably make newsreaders end up reading the headline alone. In this regard, a vague headline becomes an ostensive stimulus or a marketing tool of attracting headline readers to go beyond and completely read the entire article. The study findings on vagueness confirms Ifantidou's (2009) observation that vague or not-fully-informative-creative or metaphorical headlines being a few of a wide range of semantically underdetermined headlines-prompt newspaper readers to create ad hoc concepts in ad hoc context. He concludes that:

'Creative' and 'non-informative' types of the headlines (i.e. figurative, ambiguous, humorous, inter-textual, rhetorical, rhyming, punning) provide an excellent test-bed for the radical lexical pragmatic enrichment process relying on ad hoc concept in ad hoc context construction as the only interpretive process yielding an overall interpretation that satisfies the reader's expectations of relevance (2009, p.717).

In journalistic and pragmatic point of view, vagueness is an ostensive inferential communication stimulus whereby the headline designer deliberately writes a vague headline for his/her newspaper readers with prior expectations that they will optimise the relevance of the message of the headline using the ad hoc context to comprehend the headline information. Alternatively, vagueness in relevance theoretical framework is a framing device that forces readers to open the link containing the article to read the story to clear it. It is the stimulant of newspaper readership in the digital environment. Several studies on newspaper headlines have shown that there is a stiff competition among news sources for online news consumers (Chen, Conroy, \& Rubin, 2015) and a number of them are from the social media such as Twitter, Facebook, and Instagram (Mitchell \& Page, 2015). Owing to this fact, the online headline newspaper designers deliberately used vague lexical items or constructions that will entice people to click on the link. Such kind of vague headlines prompt creativity that is then exploited to bait readers into clicking on the newspaper headline. Similarly, Blom and Hansen (2015) also confirm this argument that vague or blurred newspaper headlines as a technical and narrative luring device that attempts to prompt curiosity and provocation for the readers to click on the headline links and read the full article. Even though Chen et al. (2015), Mitchell and Page (2015) and Greene (2013) argue that the use of vague lexical items in newspaper headlines violates the journalistic principle of integrity and correctness, and they believe that an 
informative newspaper headline is far better than the less informative one. Vague headlines are placed in the group of click bait and most people find it insulting and annoying, sceptical, blurred and misleading.

\subsection{Metaphors Use in Digital Newspaper Headlines}

This study surveyed some metaphors that appeared in 259 newspaper headlines of Mwananchi and The Citizen from 2017 July to June 2018. A metaphor was considered as the communicative device that online journalists use to create headlines that can attract people to click on the news. The metaphors identified were either based on similarity or function.The study found out that headline designers used different metaphors to compare concrete objects, people or ideas with other objects according to their shapes and structural position and functions. The data set in [11] is an illustration of a metaphor of resemblance in selected newspaper headlines from Mwananchi and The Citizen.

[11] a. Tanzania shuts down Jamii Forum over tough news rules (The Citizen, April 4, 2018).

b. Mke wa Lisu avunja ukimya (Mwananchi, September 24, 2017)

(Lisu's wife breaks the silence)

Source: Field data (2019)

Metaphorically, the phrasal verb shut down in data set [11], means that the Tanzania government has stopped the operation of the online platform, JAMII FORUM, under the new online content regulations. The metaphor stems from the verb shut (to close something or to become closed). If an object, say, a door or window is shut down, it is closed. Similarly, when JAMII FORUM was shut down; the headline designer meant that its operations were closed.The designer used shutdown metaphor as the source domain, which is relatively familiar and conceptually well structured, to articulate the target domain (stopping the operations). The headline designers used the conceptual structure of closing a door to explain the closing of Jamii Forum.

In Relevance Theory by Sperber and Wilson (1986/1995), a metaphorical headline seems to be irrelevant as it requires readers to exploit more processing efforts to yield the positive cognitive effect. However, under ostensive inferential communication, the writer of the newspaper can intend to inform his audience a about something through headlines and shows his informative intention by exploiting a metaphor that acts as the attention-drawing device to the readers.

In the headline of dataset [11.b], the phrase 'Vunja ukimya' or 'break the silence', according to The Free Online Dictionary is to voice an opinion or comment on something after initially avoiding doing so. In line with this definition and the text that followed the headline, Lisu's wife had never spoken about the murder attempt of her husband. Therefore, the wife broke the silence by speaking out what happened to her husband, Lisu. The designer of this heading used 'break the silence' metaphor as the device of attracting readers.

According to Relevance Theory by Sperber and Wilson (1985/6), the writer of the newspaper headlines in the data set [11] intended to exploit an idiom as a metaphor to reconstruct an online headline by relevance-driven inferential communication. Thus, the role of the readers was to search for an optimally relevant interpretation of metaphor to arrive at the ad hoc concept in ad hoc context. In relevance theoretical framework, a metaphor is an informative communicative device that aims at luring the online news consumers. A metaphor, in this case, is both a conceptual aspect of news representation and a literary strategy for attracting readers to click and read the entire news article (Molek-Kozakowska, 2014). Vega-Moreno (2003) used the Relevance Theory by Sperber and Wilson (1985/6) to conclude that idiomatic metaphors are constrained at every single step by the search for an optimally relevant reading.

The other metaphors that journalists used were based on the function of an object rather than its appearance. In this case, the metaphoric transfer did not involve any concrete appearance. It focused on structure functionality. The data set in [12] is an illustration of the headline with metaphors from the front pages of Mwananchi and The Citizenonline newspapers.

[12]a. Mkemia mkuu kitanzini. (Mwananchi, August 25, 2017)

(The Chief Chemist is in Gallows)

b. Lulu slapped with two-year jail term for killing Kanumba. (The Citizen, November 13, 2017)

Source: Field data (2019)

The data set in [11a] contains the Swahili metaphor kitanzini with the literal meaning that the chief chemist was in gallows. In spite of having literal meaning, the lexical gallows had the functional metaphoric similarity of executing someone by hanging. The common usage (source domain) of the term kitanzi (gallows) is the device that usually consists of two upright posts supporting a crossbeam from which a noose is suspended and used for execution by hanging. However, the same term has a non-literal and metaphorical meaning (target domain) that is used to express the hard situation that a person faces when is waiting for his or her fate.

In real sense, the headline referred to the Tanzanian Chief Government Chemist who was alleged of unregulated chemical business as he had committed a crime punishable by law (Mwananchi, August 25, 2017).Headline designer imaginatively and creatively associated the charges that the chief chemist was facing and the function of gallows. This metaphor is a good example of linguistic metaphors in newspaper headlines that would make the person read the whole news article. Under ostensive inferential communication, metaphorical headlines were stimuli that online journalists employed to provoke and lure readers to read the article.

The word slapped in the headline Lulu slapped with two-year jail term for killing Kanumbain [12.b] has the metaphorical function of the traditional punishment of quickly hitting someone with the flat part of the hand or other flat objects. In this context, the newspaper headline designer used the term slap metaphorically to explain a-two yearsof imprisonment punishment that the famous Tanzanian actress, Elizabeth Michael nicknamed Lulu, received from the court of law. In other words, the designer of the headline did not refer to the actual slapping but to the court punishment (imprisonment) given to Lulu. 
Another metaphor was based on personification. Personification in this study was defined as metaphor where an idea, a thing, or an animal receive human qualities. Through newspaper headlines, the objects that were not humans were portrayed as having the capability of performing human beings' actions. The data set in [13] is an illustration of personification metaphors as portrayed in Mwananchi and The Citizen online newspaper headlines.

[13] a. Viboko 12 vyamsubiri bilionea nyumba za Lugumi. (Mwananchi, November 16 2017) (12 strokes await the

billionaire of Lugumi's houses.)

b. NGO opens application window for higher education loan. (The Citizen, November 12017 )

Source: Field data (2019)

In headline [13.a] above, the strokes are given attributes of human being of waiting and practically, the strokes cannot wait for a human being, as they are inanimate creatures. The designer used personification metaphor as both the cognitive and conceptual element (Lakoff \&Johnson, 1987) and a literary device of attracting the attention of online newsreaders (Sperber and Wilson, 1995). This metaphor is an ostensive stimulus that is aimed at attracting the audience's attention. The same applies to the headline in the data set [13b]. An NGO (Non-Governmental Organisation) is given the human attribute of opening application. The NGO is an inanimate subject that requires an inanimate verb and object. The personification of NGO is a metaphor that journalists of the newspaper used to draw the attention of newspaper readers. The readers of the headline can use pragmatic inferential interpretation to understand what the writer has intended to communicate. Once again, personification is an ostensive inferential communication that online journalists use to entice newsreaders to click on the news.

\section{Summary, Conclusion and Recommendations}

From this study, it was revealed that The Citizen and Mwananchi newspaper headlines were informative and observed the traditional intention of a print newspaper headline of being informative by summarising the main points of the article. This implies that readers could skip reading the full article after scanning the headlines. Thus, the practical communicative function online newspaper headline was to summarise the articles they introduced. Even though some less informative headlines are not languages, the use of ambiguity, vagueness, metaphorical expressions and other forms of literary devices seemed to be used as devices that are used to attract readers to either click on the full article or use the ad hoc concepts and ad hoc contexts to interpret the headlines.

Through Relevance theory, we can therefore conclude that each headline whether informative or less informative was ostensive in that it signalled the communicative intention implicitly to its readers and readers were likely to comprehend the headlines. In other words, all headlines were relevance optimisers that aimed at minimizing the cost of processing on the side of newspaper readers and maximising cognitive effects.

The study recommended carrying out another study that would reveal how headlines published could affect readership and visibility in different such engines and social media.

\section{References}

i. Al Janaby, H. M., \& Abed, A. A. (2011). Syntactic ambiguity in newspaper headlines. Journal of the Faculty of Collective Knowledge, 16, 1-29.

ii. Alagbe, A. A. (2009). A lexico-grammatical interpretation of ambiguity and communicative effectiveness of media headlines of print media. African Research Review, 3(4),122-139.

iii. Bell, A. (1991). The language of news media. Oxford: Blackwell.

iv. Blom, J. N., \& Hansen, K. R. (2015). Click bait: Forward-reference as lure in online news headlines. Journal of Pragmatics, 76, 87-100.

v. Bonyadi, A., \& Samuel, M. (2013). Headlines in newspaper editorials: A contrastive study. SAGE Open. https://doi.org/10.1177/2158244013494863

vi. Brône, G., \& Coulson, S. (2010). Processing deliberate ambiguity in newspaper headlines: Double grounding. Discourse Processes, 47(3), 212-23.

vii. Brône, G., \& Coulson, S. (2010). Processing deliberate ambiguity in newspaper headlines: Double grounding. Discourse Processes, 47(3), 212-236.

viii. Bucaria, C. (2006). Lexical and syntactic ambiguity as a source of humour: The case of newspaper headlines. Humour - International Journal of Humour Research, 17(3), pp. 279-309. Retrieved on 4 July 2019, from https:// doi:10.1515/humr.2004.013

ix. Bucaria, C. (2006). Lexical and syntactic ambiguity as a source of humour: The case of newspaper headlines. Humour, 17(3), 279-309.

x. Chen, Y., Conroy, N. J., \& Rubin, V. L. (2015, November). Misleading online content: Recognizing click bait as false news. In Proceedings of the 2015 ACM on Workshop on Multimodal Deception Detection (pp. 15-19).ACM.

xi. Dor, D. (2003). On newspaper headlines as relevance optimizers: Journal of Pragmatics.35 (5), 695-721

xii. Fite, W. (1900). Contiguity and Similarity. The Philosophical Review, 9(6), 613-629. Retrieved from https//: doi: $10.2307 / 2176998$

xiii. Frawley, W. (2013). Linguistic semantics. Routledge.

xiv. Geeraerts, D. (2010). Theories of lexical semantics. Oxford: Oxford University Press.

xv. Gilmore, L. (2016). Public grief: Reading Joan Didion in the context of BlackLivesMatter. $a / b$ : Auto/Biography Studies, 31(3), 610-614. 
xvi. Greene, D. J. (2013). Keeping it vague: a study of vague language in an American Sign Language corpus and implications for interpreting between American Sign Language and English (Master's thesis). Western Oregon University, Monmouth, Oregon. Retrieved fromhttps://digitalcommons.wou.edu/theses/2

xvii. Grice, H. P. (1975). Logic and conversation. In Speech Acts (pp. 41-58). Brill.

xviii. Guo, W., Yu, T., \& Gimeno, J. (2017). Language and competition: Communication vagueness, interpretation difficulties, and market entry. Academy of Management Journal, 60(6), 2073-2098.

xix. Haiyan, W. (2013). A Pragmatic study of metaphorization in English Newspaper Headlines. World Academy of Science, Engineering and Technology, International Journal of Social, Behavioural, Educational, Economic, Business and Industrial Engineering, 7(10), 2822-2825.

xx. Handke, J. (2013, June 4). Semantics and Pragmatics-ambiguity. Posted on The virtual Linguistics Campus. Retrieved on $14^{\text {th }}$ July 2017 from https://www.youtube.com/watch?v=cYYUteTBtxo

xxi. Iarovici, E., \& Amel, R. (1989). The strategy of the headline. Semiotica, 77(4), 441-460. Retrieved from https://doi.org/10.1515/semi.1989.77.4.44.

xxii. Ifantidou, E. (2009). Newspaper headlines and relevance: Ad hoc concepts in ad hoc contexts. Journal of Pragmatics, 41(4), 699-720. Retrieved from https://doi.org/10.1016/j.pragma.2008.10.016.

xxiii. Kempson, R. M. (1977). Semantic theory. Cambridge: Cambridge University Press.

xxiv. Khalifa, S. (15 $5^{\text {th }}$ November 2018). The Citizen Newspaper publisher named champion in Tanzania's print media market study. The Citizen. Accessed https://www.thecitizen.co.tz/news/1840340-48533704an33qz/index.html.

xxv. Khamahani, G., \& Tahirov, I. M. (2013). Focus on structural and lexical ambiguity in English newspaper headlines written by native and non-native journalists: A contrastive study. Mediterranean Journal of Social Sciences, 4(6), 379.

xxvi. Kuiken, J., Schuth, A., Spitters, M., \& Marx, M. (2017). Effective Headlines of Newspaper Articles in a Digital Environment. Digital Journalism, 5(10), $1300 \quad$-1314.Retrieved from https://doi.org/10.1080/21670811.2017.1279978.

xxvii. Lakoff, G., \& Johnson, M. (1987). The metaphorical logic of rape. Metaphor and Symbol, 2(1), 73-79.

xxviii. Langacker, R. W. (1987). Foundations of cognitive grammar: Theoretical prerequisites (Vol. 1). Stanford California, CA: Stanford University Press.

xxix. Lindemann, B. (1990). Cheap thrills we live by: some notes on the poetics of tabloid headlines. Journal of Literary Semantics, 19 (01), 46-59.

xxx. Marquez, F. T. (1980). How accurate are the headlines? Journal of Communication, 30(3), 30-36.

xxxi. Media Council of Tanzania. (2018). State of the Media 2016. Dar es Salaam: MCT

xxxii. Mitchell, A., \& Page, D. (2015). State of the News Media. Pew Research Center.Retrieved from http://www.journalism.org/2015/04/29/state-of-the-news-media-2015.

xxxiii. Molek-Kozakowska, K. (2014). Coercive metaphors in news headlines. Brno Studies in English. 40. $149-173$. Retrieved from Doi.10.5817/BSE2014-1-8.

xxxiv. Morgan, S. E., Movius, L., \& Cody, M. J. (2009). The power of narratives: The effect of entertainment television organ donation storylines on the attitudes, knowledge, and behaviours of donors and non-donors. Journal of Communication, 59(1), 135-151.

xxxv. Nir, R. (1993). A Discourse analysis of news headlines. Hebrew Linguistics, (37), 23-31.

xxxvi. Nwala, M. A., \& Umukoro, B. A. (2017). Investigating the meaning of newspaper headlines: The issue of ambiguity. African Research Review, 11(3), 87-96.DOI: 10.4314/afrrev.v11i3.9

xxxvii. Perfetti, Charles A., Sylvia Beverly, Laura Bell, Kimberly Rodgers, and Robert Faux. 'Comprehending newspaper headlines.'Journal of Memory and Language 26, no. 6 (1987): 692-713.Retrieved from https://doi.org/10.1016/0749-596X(87)90110-0

xxxviii. Ricoeur, P. (2003). The rule of metaphor (1975). U of T Press: 0-8020-6447-7 pp384.

xxxix. Riemer, N. (2010). Introducing semantics. Cambridge: Cambridge University Press.

xl. Sabet, P. G., \& Zhang, G. Q. (2016). Communicating through vague language: A comparative study of L1 and L2 speakers. New York: Springer.

xli. Saxena, S. (2006). Headline writing. Delhi: SAGE Publications India.

xlii. Sennet, A. (2016). Philosophy, Philosophy of Language (Online Publication). Retrieved from https:// DOI:10.1093/oxford/9780199935314.013.32

xliii. Shie, J. S. (2011). Metaphors and metonymies in New York Times and Times Supplement news headlines. Journal of Pragmatics, 43(5), 1318-1334.

xliv. Silaški, N. (2009). Topic-triggered metaphors in newspaper headlines. Professional Communication and Translation Studies, 2(1-2).

xlv. Sperber, D \& Wilson, D (1986). Relevance: Communication and Cognition. Vol.142. Oxford: Blackwell.

xlvi. Sperber, D., \& Wilson, D. (1995). Relevance: Communication and Cognition. Oxford: Blackwell.

xlvii. Van Dijk, T. A. (1988). News as discourse. Hillsdale: Lawrence Erlbaum Associates

xlviii. Vega-Moreno, R. E. (2003). Relevance Theory and the construction of idiom meaning. UCL Work Pap Ling, 15, 83-104.

xlix. Yamane, T. (1967) Statistics: An introductory analysis, Second edition. New York: Harper and Row. 